\title{
PERSPECTIVES
}

SCIENCE AND SOCIETY

\section{Smallpox: anything to declare?}

\section{Geoffrey L. Smith and Grant McFadden}

Smallpox was eradicated in 1977 , but it remains a concern owing to the potential use of the causative agent variola virus in bioterrorism. This article provides an overview of the World Health Organization's spectacular success in achieving the eradication of smallpox. It discusses how variola virus could potentially re-emerge and how prepared we are to counter such a re-emergence. Finally, the potential threat from other orthopoxviruses that exist naturally or that have been genetically engineered is considered. In the words of Rep. Christopher Shay, 'Better to be scared by the improbable possibility than to be unprepared for the catastrophic reality'.

Although smallpox was eradicated from the human population more than two decades ago, fears about its potential re-emergence have not subsided ${ }^{1-5}$. Indeed, the events of 11 September, 2001 and the subsequent anthrax attacks in the United States have heightened anxiety about the potential for the deliberate release of variola virus, the causative agent of smallpox, as an act of war or terrorism ${ }^{6-11}$. The issue is complicated further by the fact that the debate about the fate of the known variola-virus stocks is shaped largely by an essentially unanswerable question - namely, do undeclared stocks of variola virus still exist today in a form that is accessible to either rogue governments or terrorists? Dialogue on this subject became more polarized after allegations that variola virus stocks had been prepared in exceedingly large quantities in a weaponized form by Biopreparat, the Soviet bioweapons programme, in the 1980s and early $1990 \mathrm{~s}^{12,13}$. The existence of any of these undeclared stocks of variola virus has never been officially verified, and the undocumented nature of these reports only fuels the acrimony that is generated by this debate ${ }^{1,6-9}$. Despite the differences between those in favour of the retention of virus stocks and those in favour of their destruction ${ }^{6,7,9,14-16}$ (BOX 1), most parties agree on the fundamental conundrum that confronts us all: what is the best way to minimize the possibility of the re-emergence of smallpox, anywhere on the globe?

As history has shown all too well, smallpox can have catastrophic consequences on global public health ${ }^{1,17,18}$. In this article, we examine the controversy that surrounds declared versus undeclared variola virus stocks. Even if it is impossible to determine whether undeclared variola stocks still exist in

\section{Box 1 | Declared stocks of variola virus: retention versus destruction}

The controversy over whether to retain or destroy the two declared stocks of live variola virus (Centers for Disease Control, Atlanta, USA and Novosobirsk, Russia) began in earnest when the World Health Organization (WHO) certified the world free of smallpox in 1980, and it continues to this day. The arguments that are put forward by both camps are summarized below.

Pro-destruction

- Final destruction is the logical conclusion of the WHO eradication programme.

- The two declared stocks could be the source of a future release.

- The current vaccinia-based vaccine is efficacious.

- Surrogate poxviruses provide adequate models for research.

- Genomic DNA sequencing of representative variola strains has been completed.

- Cloned DNA fragments provide sufficient repository function.

- Destruction will exert moral pressure on terrorists or rogue nations that variola weaponization is a crime against humanity.

Pro-retention

- The re-emergence of smallpox is possible by many scenarios (for example, from corpses in permafrost, inadvertent laboratory stocks and rogue sources).

- Undeclared stocks are a greater danger than the two declared ones.

- Destruction will result in complacency, rather than vigilance.

- More research into anti-variola drugs and vaccines is required, and live virus is needed to test these reagents.

- The current vaccinia virus vaccine is inadequate for many people who are immunocompromised or who have medically counterindications (such as eczema).

- Surrogate orthopoxviruses are inadequate to verify any new anti-variola strategies (Food and Drug Administration, United States).

- Future research with variola virus might yield new insights into virus interactions with the human immune system.

- Terrorists and rogue nations are unlikely to be influenced by moral persuasion. 


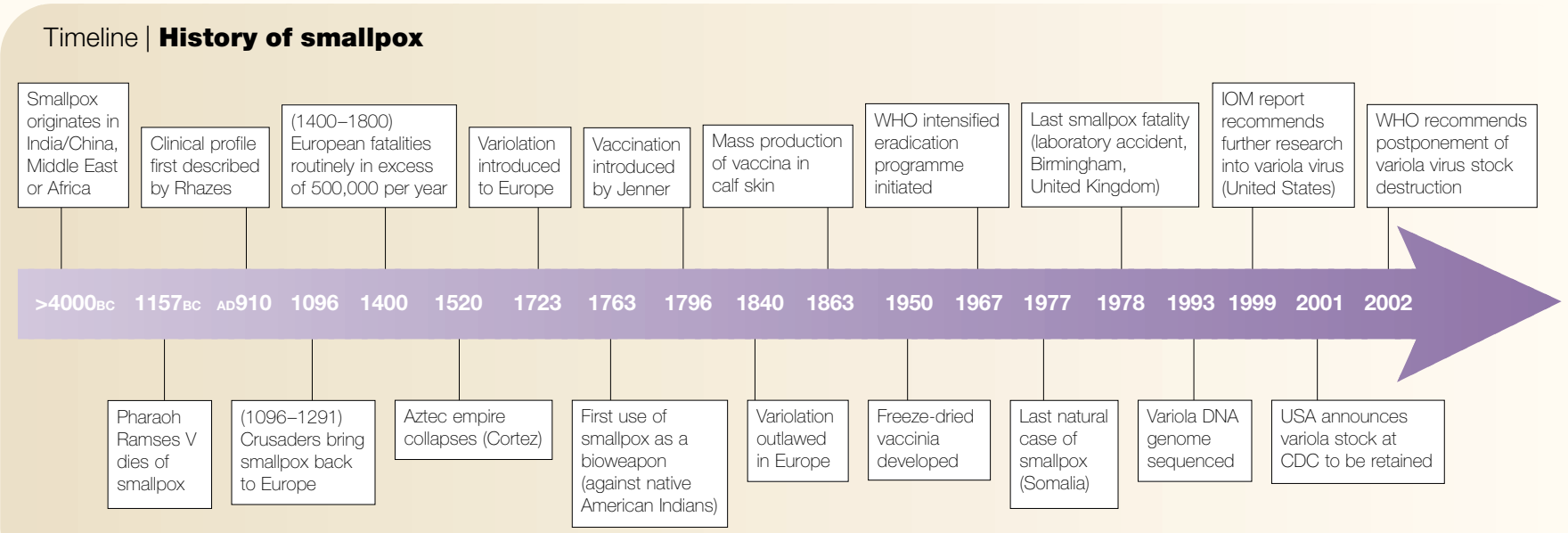

CDC, Centers for Disease Control; IOM, Institute of Medicine; WHO, World Health Organization.

2002, or who might have access to such stocks, there are important decisions that face the World Health Organization (WHO) and the global community concerning the fate of the two declared stocks.

\section{The eradication of smallpox}

Smallpox is the only human disease to have been eradicated, and this accomplishment remains one of the greatest triumphs of modern medical science (SEE TIMELINE). The first control measure for smallpox was variolation, a process in which live variola virus was taken from a person with smallpox and administered to an uninfected individual. This process had a mortality rate of approximately $1 \%$ - an alarming figure, but far lower than the mortality that resulted from natural infection by the respiratory route (up to $40 \%$ ). Variolation had been practised in India and China for centuries before it was introduced into Western Europe in 1723 by Lady Wortley Montagu, the wife of the British ambassador in Constantinople, who noticed the practice being carried out by the Turks. It was used widely in parts of Western Europe as the only means of protection against smallpox until Jenner introduced vaccination in 1796 (FIG. 1). Jenner noticed that milkmaids were sometimes infected on their hands with a selflimiting contagious agent as a result of milking cows and that they were protected subsequently against smallpox. Although Jenner was not the first to notice this correlation, he was the first to test systematically the hypothesis that infection with this cowderived poxvirus protected against smallpox. Jenner took material from the lesion of a milkmaid, Sarah Nelmes, and vaccinated a boy, James Phipps, whom he subsequently challenged with variola virus. The boy remained free of smallpox and, after additional study,
Jenner published his famous paper on the subject, which marked the beginning of the vaccination era. The practice of vaccination replaced variolation rapidly and its success led Jenner to predict in 1801 , “...that the annihilation of the smallpox, the most dreadful scourge of the human species, must be the final result of this practice."19

For his discovery and promotion of vaccination, Jenner received many accolades, including a stipend from the British Parliament, which was subsequently doubled. The magnitude of his discovery was summarized perfectly by the President of the United States, Thomas Jefferson, who said in 1802, "Medicine has never before produced any single improvement of such utility. You have erased from the calendar of human afflictions one of its greatest."

Given the potency of vaccination, why did the eradication of smallpox take nearly two centuries to accomplish? Some of the problems were technical — for example, there was a limited supply of vaccine, because cowpox was a relatively rare disease of Western Europe and was absent in the Americas. To transport the live vaccine from Europe to central America, the Spanish used orphan children from Cadiz and passaged the virus by arm-toarm transfer on the long voyage across the Atlantic. Eventually, human-to-human transmission was banned because of the transmission of other pathogens, such as measles and syphilis. Despite the widespread use of smallpox vaccine, little progress towards global eradication was made until after the development of freeze-dried vaccine in 1950. This enabled the vaccine to be maintained, transported and used under field conditions without refrigeration or loss of potency. In 1959, the WHO adopted a resolution that was proposed by the Soviet Union to achieve the global eradication of smallpox. Despite renewed efforts, little progress was made until 1967 , when the policy of mass vaccination was modified to one that had greater emphasis on surveillance and containment. Using the method of ring vaccination, new cases of smallpox were identified and quarantined rapidly, and close contacts of infected individuals were also vaccinated and quarantined. In this way, the chain of human-to-human infection was stopped and each epidemic was contained. This policy was successful in achieving the eradication of smallpox from the Indian sub-continent by 1975 , and the last naturally occurring case of smallpox was diagnosed in Somalia in 1977. Just over two years later, after extensive surveillance throughout the world, the WHO confirmed the fulfillment of Jenner's prophecy ${ }^{20}$.

The eradication of smallpox is the most spectacular success of the WHO. It proves unequivocally the principle that prevention is better than cure and that this is best achieved by eradication. The eradication of smallpox was assisted by several important properties of both the vaccine and the disease, which have implications for the control of other infectious diseases. First, smallpox was restricted to humans, and the virus did not persist in animal reservoirs. This species restriction is contrasted with, for example, rabies and yellow fever, either of which might be re-introduced into humans from other mammals or insect vectors, respectively. Second, variola virus cannot establish latent or persistent infections, so that once infected, a patient either died or they recovered, cleared all infectious virus and became immune. Third, the symptoms of smallpox were recognized easily, so that infected individuals could be quarantined and their contacts vaccinated. By contrast, HIV-1 spread 


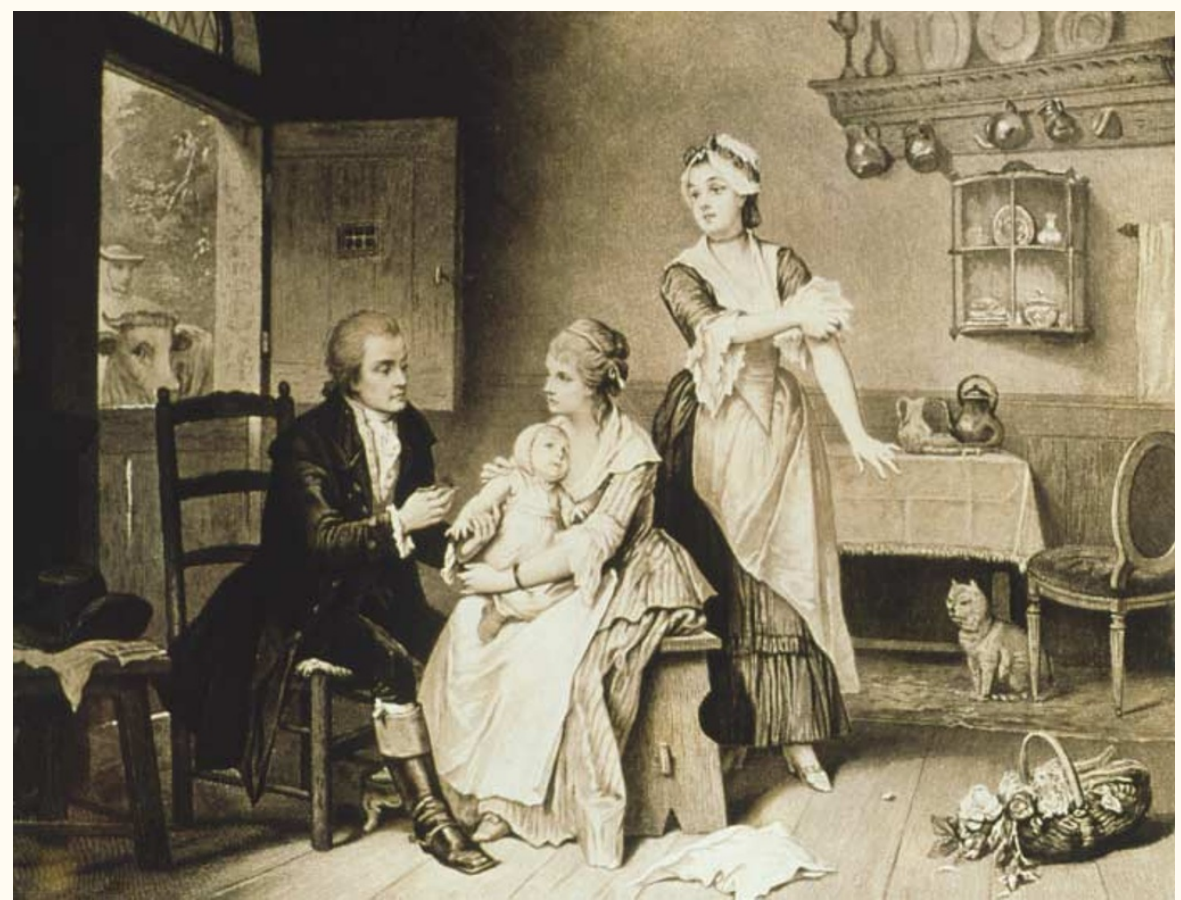

Figure 1 Smallpox vaccination. Historical engraving of Edward Jenner (1749-1823) vaccinating a baby against smallpox. In 1796, Jenner coined the term 'vaccination' to describe his use of cowpox inoculation to obtain immunity to smallpox. Jenner experimented on an 8-year-old boy (James Phipps) by inoculating him with fluid obtained from a blister on the hand of a milk-maid (Sarah Nelmes) who had cowpox. He later inoculated the boy with smallpox. The boy survived and did not contract smallpox. Vaccination against smallpox soon became widespread. () 2002 Science Photo Library.

unseen in the human population for many years before the first cases of AIDS were identified in the United States in 1981; consequently, the HIV epidemic was already out of control before anyone knew that it existed. Fourth, the smallpox vaccine was effective against all strains of variola virus and these strains were unable to undergo antigenic variation to escape existing immunity (because the poxvirus DNA polymerase has high replication fidelity), in contrast with HIV and influenza virus. Finally, the vaccine was cheap, plentiful, potent, stable without refrigeration, effective, and easy to manufacture and administer.

After the eradication of smallpox was certified in 1980, there were many who saw the destruction of the remaining stocks of variola virus as the logical completion of the eradication campaign ${ }^{6,7,9}$. Advocates of this policy stated that this would eliminate the risk of accidental release of the virus and prevent the repetition of a tragic laboratory accident in Birmingham, United Kingdom in 1978 (REF. 21). Towards this goal, under the direction of the WHO, all known stocks of variola virus throughout the world were centralized in two maximum-security laboratories in Russia and the United States, which, today, are the only official places where declared variola virus stocks are maintained. Variola virus has been scheduled for destruction several times in the past two decades, but each time, the destruction has been postponed to allow further research with the live virus $^{22}$. Such research projects are all considered carefully and monitored strictly by the $\mathrm{WHO}^{23}$.

The terrible events of 11 September, 2001 raised the political and public awareness of the global threat of terrorism. Shortly thereafter, the fears of bioterrorism, in particular, were exacerbated by the deliberate release of
Is the re-emergence of variola virus a cause for concern? minor virus. the same genus.

- There are no licensed drugs to treat smallpox. for more than 20 years.

- The available vaccine is old and in limited supply. least 9-11 days later. anthrax in the United States. If fanatics were prepared to commit suicide and mass murder by flying aeroplanes into densely populated buildings, would such individuals hesitate to use biological weapons, such as smallpox, if these were available? In view of this threat, several countries have started to manufacture smallpox vaccine to replenish their depleted and ageing stocks ${ }^{24}$. Furthermore, intense debate about the potential consequences of the use of smallpox for biowarfare has penetrated to the highest levels of governments around the world.

\section{The feared scenario of re-emergence}

There are various reasons for the escalated fears about the potential for smallpox reemergence (BOX 2). Twenty-five years since the last natural case of smallpox, most of the world's population has never been immunized against smallpox. To provide continuous protection against smallpox, it was recommended that individuals in endemic areas should be vaccinated every three years. So, it is probable that those who were vaccinated more than two decades ago would no longer be protected against infection, although the disease might be controlled in some of the former vacinees ${ }^{25}$. In 1978 in Birmingham, United Kingdom, a person who contracted smallpox because of a laboratory accident died of the disease despite having been vaccinated 12 years before.

If a deliberate and unannounced release of variola virus were to occur in a public place, there would be no knowledge of this event for about 9-11 days, until the first symptoms appeared in infected persons ${ }^{2,26}$. By this time, those individuals who were infected would probably have disseminated widely throughout the world and would, subsequently, become contagious once lesions appeared in the oropharynx. This crisis would present health officials globally with the daunting, perhaps impossible, task of tracking all of the

\section{Box 2 | Variola virus, smallpox and bioterrorism}

- Mortality rates vary from $40 \%$ for variola major virus to $1-2 \%$ for the less virulent variola

- Smallpox is prevented by previous vaccination with vaccinia virus, which is a related virus of

- Vaccination also has some benefit up to four days after infection.

- Much of the world's population has either never been immunized or has not been immunized

- A covert release in a public place would cause infections that would not be apparent until at 
individuals who might have been exposed. The dissemination of smallpox today would be more rapid and extensive than 25 years ago owing to the vastly increased use of air travel.

If a case of smallpox was diagnosed and verified, many difficult issues would immediately arise. Is there an isolation facility available and are there vaccinated ambulance staff to transport patients to the site? Are the health-care staff of this facility (recently) vaccinated and prepared to be quarantined for at least three weeks? Without vaccination, the probability of infection for close contacts is $40-90 \%$. If the epidemic expanded, would there be sufficient facilities and staff to cope? Is there enough vaccine available for prompt use? Which vaccine should be used (see below)? Should governments order the suspension of travel between any country that had smallpox cases and its own territory, effectively closing borders? Would travel be allowed with a vaccination certificate? The difficult questions that would be faced by all levels of government and health-care systems would quickly assume unmanageable proportions.

Although a wealth of historical information exists about how smallpox could spread through human populations during times when the virus was endemic, it is less clear how quickly the virus would disseminate in the modern age, in which most of the population possesses little or no herd immunity ${ }^{27}$. Perhaps an historical analogy is the penetration of smallpox through the immunologically naive Aztec population of central America after the arrival of the Spanish conquistadors in the early part of the 16th century. Here, the news is not at all encouraging, because the rampant spread of smallpox caused millions of casualties and essentially ended the Aztec Empire ${ }^{1}$.

Despite the uncertainties of predicting human-to-human transmission parameters in the modern world, theoretical modelling has been used to predict the possible consequences of a single terrorist attack with smallpox $^{28-30}$. These scenarios forecast widespread social disruption as the health-care crisis expands faster than the combined efforts of quarantine and vaccination can respond. Assuming a transmission rate of three new cases per infected person, calculations indicate that a single focal outbreak would result in the spread of infection for up to one year, until vaccination and quarantine strategies caught up ${ }^{30}$.

A theoretical release model was provided by the Dark Winter exercise, carried out in June 2001 in the United States ${ }^{31}$. This simulation was based on a single release of variola

\section{Box 3 | Lessons from the Dark Winter exercise}

- In June 2001, a theoretical smallpox release in the United States was modelled to evaluate the response capacities of the health-care sector.

- Crucially, weeks passed after the initial release before the definitive identification of the outbreak as smallpox.

- Leadership hierarchies were complicated and jurisdiction issues remained unresolved for important questions relating to vaccine distribution and quarantine commands.

- A minimal surge capacity to handle an escalated case load limited the responses of the healthcare sector.

- The rapid vaccination of health-care workers was problematic, as was formulating a broader vaccination strategy.

- Mechanisms of mass quarantine were not in place, or were not enforceable.

- Conflicts between local, regional and national authorities arose concerning the control of vaccine distribution.

- The individual actions of citizens were unpredictable and were not always consistent with national public-health priorities (particularly in quarantine scenarios).

virus in Oklahoma City, modelled as an initial outbreak of 20 cases of smallpox, which, within relatively few months after diagnosis, overwhelmed the North American publichealth system (see Further Information websites). Several factors prevented the effective containment of this hypothetical epidemic the most important of these are summarized in BOX 3. In short, a release of variola virus for whatever reason would probably quickly escalate into a national, and then a global, health emergency.

In view of these concerns, what is the probability that any undeclared variola-virus stocks exist? There are two potential categories of undeclared stocks - military and non-military. The latter consists of live virus that might still exist in the bodies of smallpox victims that are frozen in the permafrost, or inadvertent laboratory stocks that were never recognized during the $\mathrm{WHO}$-directed centralization of variola virus stocks in the 1970s and 1980s. No evidence for either source has been documented so far, but the possibility cannot be discounted ${ }^{1,11}$. Unfortunately, the probability of any clandestine military source of variola virus is not known with any verifiable accuracy. So, any debate about the fate of the two declared, WHO-ratified stocks (Centers for Disease Control, Atlanta, United States and Novosibirsk, Russia) cannot presume that the destruction of these two stocks will eliminate the risk of a future release. In essence, the question becomes as follows: would the elimination of the two WHOapproved stocks make the world safer from smallpox, or would it actually increase the potency of any release from an undeclared source? It is this and other issues that divide the pro-destruction and pro-retention camps (BOX 1).

\section{Do other poxviruses pose a threat?}

Variola virus is an orthopoxvirus, a genus of poxviruses that infect chordates ${ }^{32}$. Other related members of this group include cowpox, vaccinia, monkeypox, ectromelia (mousepox), taterapox and camelpox viruses (FIG. 2). Monkeypox virus can cause a human disease that is visually very similar to smallpox and that is associated with significant morbidity and mortality. However, unlike smallpox, the transmission of monkeypox from person to person is inefficient and outbreaks tend to be sporadic with little spread from the index case ${ }^{33}$. The virus appears sporadically in west and central Africa and might be transmitted to humans by monkeys or rodents. Its natural reservoir is probably rodents, with infections of humans and monkeys being zoonoses. Nevertheless, the potential of monkeypox virus to cause significant disease in humans exists, and the growing number of individuals who are immunosuppressed owing to HIV infection increases the potential of monkeypox virus to cause serious human disease.

Camelpox virus was of concern during the smallpox-eradication campaign, owing to its description as 'smallpox-like' ${ }^{34}$. Camelpox virus causes severe disease only in camels. It has several biological properties that are similar to variola virus in humans, which are distinct from other orthopoxviruses; but, despite these similarities, there have been no reports of camelpox-virus infection of humans, even though humans who handle infected camels would have been exposed to the virus.

Recently, the genome sequences of monkeypox virus and camelpox virus have been determined ${ }^{35,36,44}$. Phylogenetic analyses of these sequences show that camelpox and variola viruses are very closely related, whereas 
monkeypox virus is quite distinct and has diverged from the other orthopoxviruses a long time ago. Therefore, the probability of monkeypox virus mutating into variola virus is likely to be remote. However, the genetic changes that would be required for monkeypox virus to be more easily transmitted from human to human are unknown, and such an alteration would be a major concern. Moreover, if this change occurred while retaining the virus' ability to persist in animal reservoirs, we would be faced with a new virus that produced a smallpox-like disease that could be introduced into the human population from animals.

In the case of camelpox virus, the genomic similarity to variola virus indicates that these viruses have diverged more recently. There remain, however, differences between these viruses, so that the generation of variola virus from camelpox virus by spontaneous mutation is not probable. Nevertheless, the genetic manipulation of camelpox virus so as to delete genes that are absent in variola virus or repair any of the genes that are disrupted in camelpox virus, but intact in variola virus, might be dangerous.

On a related note, could variola virus or other orthopoxviruses be engineered genetically to make them more dangerous? One approach would be to engineer a variola virus variant that is sufficiently different in terms of its surface proteins to escape the immune response that is induced by the smallpox vaccine. In practice, this would be very difficult to accomplish, because variola virus has many envelope proteins that are highly conserved between vaccinia virus and other orthopoxviruses. An alternative strategy was indicated by a recent study with ectromelia virus (the cause of mousepox). In an attempt to create a virally vectored immunocontraceptive vaccine, Australian researchers introduced genes into ectromelia virus that encode the mouse Thelper $2\left(\mathrm{~T}_{\mathrm{H}} 2\right)$ cytokine interleukin-4 (IL-4) to boost antibody responses. The resulting recombinant virus was more virulent than the parent virus and killed mice that were genetically resistant to wild-type virus ${ }^{37}$. Of greater concern was the indication that mice that had been immunized previously and, supposedly, were immune to challenge with wild-type ectromelia virus were also killed by the IL-4expressing recombinant virus. By extrapolation, the implication is that a variola virus that was engineered to express human IL-4, or possibly another $\mathrm{T}_{\mathrm{H}} 2$ cytokine, might become more virulent and even overcome the immunity that is induced by standard smallpox vaccination. In the absence of

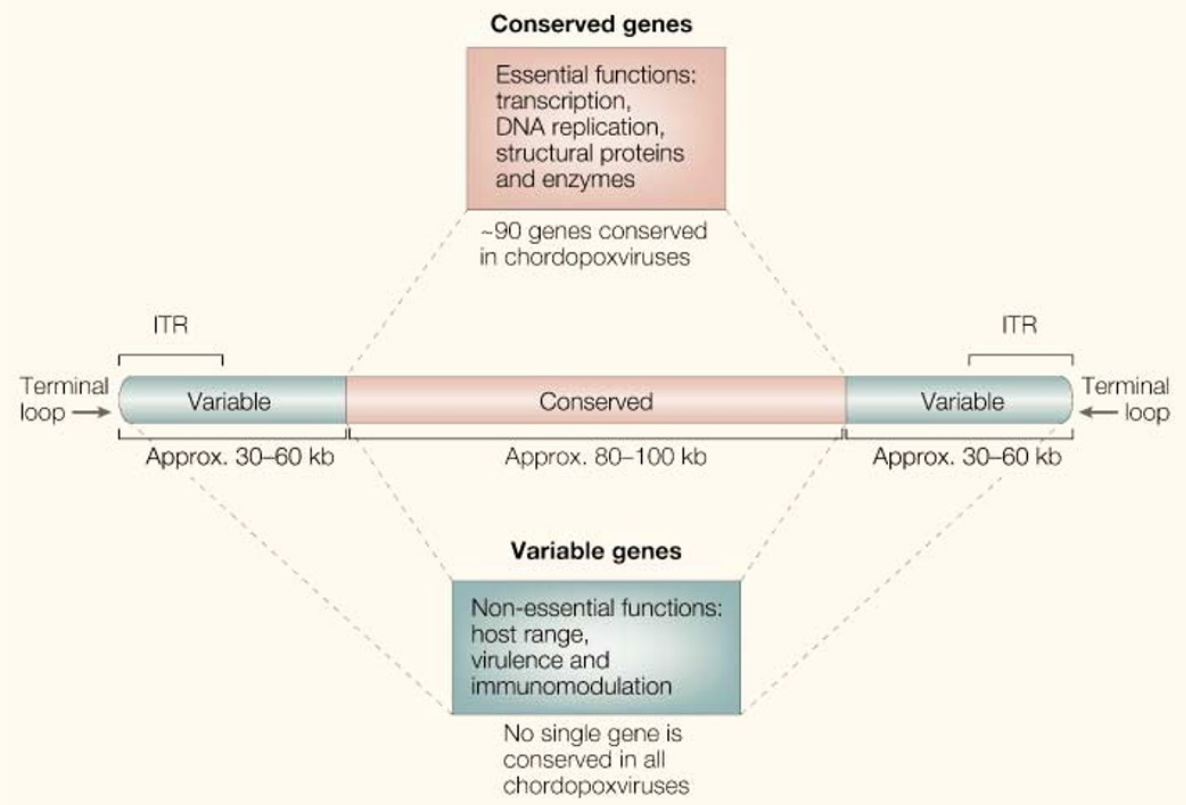

Figure 2 | A schematic representation of the orthopoxvirus genome. The average genome is approximately $200 \mathrm{~kb}$ long. Near the termini, there are inverted terminal repeats (ITRs) that vary from $\sim 0.65 \mathrm{~kb}$ in variola virus strain Bangladesh-1975 to $\sim 12 \mathrm{~kb}$ in vaccinia virus strain Copenhagen. The genome might be divided into a central conserved region, which mainly encodes conserved genes that are essential for virus replication, and terminal regions that are more variable and encode proteins that are non-essential for virus replication in cell culture. The length of the central conserved region is fairly constant between chordopoxviruses, but the terminal regions vary in length. Phylogenetic comparisons of orthopoxviruses show that: variola virus is most closely related to camelpox virus; cowpox virus and vaccinia virus are closely related; ectromelia virus groups with camelpox virus, variola virus, vaccinia virus and cowpox virus, but is the most divergent member of this sub-group; and monkeypox virus is quite divergent from all other orthopoxviruses, despite causing a disease that is similar to smallpox in humans.

effective drugs to combat smallpox, such a recombinant variola virus would be exceedingly dangerous and potentially uncontrollable. Although this report received considerable attention ${ }^{38}$, it remains uncertain whether the extrapolation of these results to variola virus is appropriate. Previous studies of the expression of IL-4 by vaccinia virus showed a more modest increase in virus virulence ${ }^{45}$, and, so, more needs to be learned about the immunological control of orthopoxvirus infections before this potential risk can be evaluated.

\section{The need for safer smallpox vaccines}

Although the smallpox vaccine is the only vaccine to have been used to achieve the global eradication of a human disease, the vaccine has an imperfect safety record and some health-care officials welcomed the eradication of smallpox not only as the end of a dreadful disease but also as an end to the need for smallpox vaccination and the complications that ensued ${ }^{20,39}$. These complications were of several types. The first was accidental infection of the vaccinee or close contacts caused by the transmission of virus from the inoculation site. The outcome was usually benign unless virus was transferred to higher-risk groups (see below) or to the eye. Second, there were generalized infections (systemic rash) that resulted from vaccination, which usually cleared without adverse sequelae. Third, there were more severe infections in vaccinees that had eczema or immunological deficiency, both of which were considered to be medical contraindications to smallpox vaccination. In particular, deficiency in cell-mediated immunity was associated with a grave prognosis, and progressive vaccinia infections in such patients could be life-threatening. Finally, a small percentage of vaccinees had severe neurological complications (in particular, encephalitis) that were unpredictable and dangerous. An extensive study in the United States in the late 1960s reported 570 complications and nine deaths as a result of 14.2 million vaccinations using the New York City Board of Health (NYCBH) vaccine ${ }^{39}$. Complication rates were at least as great with the Lister strain of vaccine that was used in Europe and other parts of the world ${ }^{20}$.

Such rates of complication of vaccination are unacceptable for a modern-day vaccine. Even before the eradication of smallpox was 
completed, several attenuated strains of vaccinia virus were being developed as candidate vaccines, such as modified vaccinia virus Ankara (MVA) and LC16m8. Although there is little doubt that these modified strains are attenuated in humans compared with the Lister or NYCBH vaccines, these vaccines were never used in the face of endemic smallpox and, therefore, there is no certainty that they are effective at preventing smallpox ${ }^{24}$. Moreover, smallpox was a strictly human disease and, at present, there are no suitable animal models to test the potency of these candidate vaccines. However, animal models might be developed, as indicated by the recent observation that the intravenous injection of variola major virus can induce mortality in monkeys owing to a smallpoxlike disease (P. D. Jahrling, personal communication). Consequently, when faced with the decision to produce new stocks of smallpox vaccine, most countries have decided to use previously verified vaccine strains (or plaque-purified derivatives of these), rather than safer attenuated variants that have unproven efficacy.

Today, immunodeficiency and eczema are far more common than a generation ago and, therefore, the need to produce safer vaccines is even greater. Some of the information that has been gained from the detailed study of vaccinia virus gene functions can be used to create engineered virus strains that are attenuated rationally, such that they have diminished replication, spread or immunomodulation of the host response to infection. Attenuation that is achieved by the deletion of specific poxvirus genes prevents the reversion to virulence that is sometimes associated with live virus vaccines for which single or multiple point mutations contribute to the attenuated phenotype. However, the development of any new-generation smallpox vaccine is hampered, as for the existing attenuated strains, by the lack of an adequate animal model in which to test efficacy. Furthermore, we do not have an adequate understanding of the immune responses that correlate with immune protection.

\section{Antivirals and antibodies}

Attempts have been made to develop targeted drugs and antibodies to combat poxvirus infections, but all of the reagents that were tested in the past against smallpox were of little benefit and were not used to any great extent. Antibody therapy was not used widely for smallpox, not least because of the lack of reagents, but the administration of vaccinia immune globulin was of benefit in treating some complications of smallpox vaccination.
Therefore, the continued development of effective polyclonal and monoclonal antibodies that are able to neutralize variola virus infectivity is desirable. Attempts to develop killed orthopoxvirus vaccines that contained inactivated preparations of intracellular mature virus (IMV) were uniformly unsuccessful, whereas vaccines that included or expressed the antigens that are present only on the extracellular enveloped virus (EEV) gave more encouraging results ${ }^{40,41}$. This indicates the importance of including EEV-specific antigens in any future smallpox vaccines and developing high-affinity antibodies that are directed against these proteins for immunotherapy.

Although no drug has ever been used successfully to combat smallpox, several promising candidates have been screened in vitro in recent years against orthopoxviruses, including variola virus. Of particular note is cidofovir and its derivatives. Cidofovir is a nucleoside analogue that is licensed for the treatment of cytomegalovirus infections, but it is also a potent inhibitor of orthopoxvirus replication. The safety and pharmacological properties of cidofovir in humans are well documented, and it might be used against smallpox in an emergency, although its administration requires intravenous delivery. However, a recent derivative of cidofovir, hexadecyloxypropyl-cidofovir (HDP-cidofovir), can be administered orally and is 100-200-fold more active against poxviruses in culture ${ }^{42}$. However, there is no certainty that cidofovir or HDP-cidofovir would be therapeutic, because, as yet, there is no adequate animal model for variola virus infection in which to test drug efficacy. Surrogate models, such as cowpox virus in mice or monkeypox virus in primates, although helpful, cannot provide any guarantee of efficacy against variola virus in humans.

\section{Conclusions}

The debate about whether to destroy the two remaining stocks of variola virus or retain them for further research is complicated by overlapping issues of science, politics and ethics. No one can predict future scientific advances in our knowledge of viral pathogenesis or whether humanized animal models of poxvirus infection could one day be developed as surrogate systems to investigate smallpox virulence. But, we can safely assume that the current fears about the possible existence of undeclared variola virus stocks will not subside in the near future. Given the current climate of distrust and anxiety concerning biological warfare, it seems unavoidable that whatever decision is made about the fate of the declared stocks, this issue will be hotly debated. So far, the WHO has permitted experimentation on variola virus, which is subject to periodic and transparent international scrutiny. The international community might not agree on a single solution for the fate of the declared stocks of variola virus, but any decision about the retention or destruction of the virus should be explained fully. Similar issues that involve the destruction of other pathogens will arise in the future, and in the case of poliovirus, the issue is already being considered ${ }^{43}$.

\section{Geoffrey L. Smith is at the Department of Virology, The Wright-Fleming Institute, Faculty of Medicine, Imperial College of Science, Technology and Medicine, St Mary's Campus, Norfolk Place, London W2 1P6, UK. Grant McFadden is at The John P. Robarts Research Institute, University of Western Ontario, Department of Microbiology and Immunology, 1400 Wester Road, London, Ontario N6G 2K5, Canada. e-mails:glsmith@ic.ac.uk; mcfadden@rri.ca} doi:10.1038/nri845

1. Tucker, J. B. Scourge: The Once and Future Threat of Smallpox (Atlantic Monthly Press, New York, 2001).

Henderson, D. A. et al. Smallpox as a biological weapon. J. Am. Med. Assoc. 281, 2127-2137 (1999).

3. Lane, H. C., La Montagne, J. \& Fauci, A. S. Bioterrorism a clear and present danger. Nature Med. 7, 1271-1273 (2001).

4. Razzell, P. Should remaining stocks of smallpox virus be destroyed? Soc. Hist. Med. 8, 305-307 (1995).

5. Ellner, P. D. Smallpox - gone but not forgotten. Infection 26, 263-269 (1998).

6. Birmingham, K. Hopkins Dean criticizes smallpox research. Nature Med. 8, 197-198 (2002).

Henderson, D. A. Countering the posteradication threat of smallpox and polio. Clin. Infect. Dis. 34, 79-83 (2002).

8. Leduc, J. W. \& Jahrling, P. B. Strengthening national preparedness for smallpox: an update. Emerg. Infect. preparedness for smallp.x:
Dis. 7, 155-157 (2001).

9. Sharma, R. WHO dissenter warns against plans to retain smallpox virus. BMJ 324, 69 (2002).

10. Brundtland, G. H. Smallpox revisted. J. Am. Med. Assoc 287, 1104 (2002).

11. Enserink, M. \& Stone, R. Public health. Dead virus walking. Science 295, 2001-2005 (2002).

12. Alibek, K. Biohazard (Random House, New York, 1999).

13. Miller, J., Engelberg, S. \& Broad, W. Germs (Simon \& Schuster, New York, 2001).

14. Mahy, B. W. J. et al. The remaining stocks of smallpox virus should be destroyed. Science 262, 1223-1224 virus shoul

15. Roizman, B., Joklik, W., Fields, B. \& Moss, B. The destruction of smallpox virus stocks in national repositories: a grave mistake and a bad precedent. Infect. Agents Dis. 3, 215-217 (1994).

16. Joklik, W. K., Moss, B., Fields, B. N., Bishop, D. H. L. \& Sandakhchiev, L. S. Why the smallpox virus stocks should not be destroyed. Science 262, 1225-1226 (1993).

17. Breman, J. G. \& Henderson, D. A. Diagnosis and management of smallpox. N. Engl. J. Med. 346, 1300-1308.

18. Barquet, N. \& Domingo, P. Smallpox: the triumph over the most terrible of the ministers of death. Ann. Intern. Med. 127, 635-642 (1997).

19. Jenner, E. The Origin of the Vaccine Inoculation (Shury, D. N., London, 1801)

20. Fenner, F., Anderson, D. A., Arita, I., Jezek, Z. \& Ladnyi, I. D. Smallpox and its eradication. World Health Organisation (1988).

21. Shooter, R. A. Report of the investigation into the cause of the 1978 Birmingham smallpox occurrence. London: H. M. Stationery Office (1980).

22. Stone, R. WHO puts off destruction of U. S., Russian caches. Science 295, 598-599 (2002).

23. WHO Advisory Committee on Variola Virus research report of the third meeting, 3-4 December, 2001, Geneva, Switzerland. WHO/CDS/CSR/GAC/2002-3 (2001). 
24. Rosenthal, S. R., Merchlinsky, M., Kleppinger, C. \& Goldenthal, K. L. Developing new smallpox vaccines. Emerg. Infect. Dis. 7, 920-926 (2001).

25. Cohen, J. Smallpox vaccinations: how much protection remains? Science 294, 985 (2001).

26. Henderson, D. A. Smallpox: clinical and epidemiologic features. Emerg. Infect. Dis. 5, 537-539 (1999).

27. Gani, R. \& Leach, S. Transmission potential of smallpox in contemporary populations. Nature 414, 748-751 (2001).

28. O'Toole, T. Smallpox: an attack scenario. Emerg. Infect. Dis. 5, 540-546 (1999).

29. Bardi, J. Aftermath of a hypothetical smallpox disaster. Emerg. Infect. Dis. 5, 547-551 (1999).

30. Meltzer, M. I., Damon, I., LeDuc, J. W. \& Millar, J. D. Modelling potential responses to smallpox as a bioterrorist weapon. Emerg. Infect. Dis. 7, 959-969 (2001).

31. O'Toole, T., Mair, M. \& Inglesby, T. V. Shining light on 'Dark Winter'. Clin. Infect. Dis. 34, 972-983 (2002).

32. Esposito, J. J. \& Fenner, F. In Fields Virology 4th edn Vol. 2 (eds Knipe, D. M. \& Howley, P. M.) 2885-2921 (Lippincott, Williams \& Wilkins, Philadelphia, 2001).

33. Hutin, Y. J. F. et al. Outbreak of human monkeypox, Democratic Republic of Congo, 1996-1997. Emerg. Infect. Dis. 7, 434-438 (2001).

34. Baxby, D. Smallpox-like viruses from camels in Iran. Baxby, D. Smallpox-like vir

35. Shchelkunov, S. N. et al. Human monkeypox and smallpox viruses: genomic comparison. FEBS Lett. $\mathbf{5 0 9}$ 66-70 (2001).

36. Gubser, C. \& Smith, G. L. The sequence of camelpox virus shows it is most closely related to variola virus, the cause of smallpox. J. Gen. Virol 83, 855-872 (2002).

37. Jackson, R. J. et al. Expression of mouse interleukin- 4 by a recombinant ectromelia virus suppresses cytolytic lymphocyte responses and overcomes genetic

resistance to mousepox. J. Virol. 75, 1205-1210 (2001).

38. Mullbacher, A. \& Lobigs, M. Creation of killer poxvirus could have been predicted. J. Virol. 75, 8353-8355 (2001).

39. Lane, J. M., Ruben, F. L., Neff, J. M. \& Millar, J. D. Complications of smallpox vaccination, 1968. National surveillance in the United States. N. Engl. J. Med. 281 1201-1208 (1969).

40. Boulter, E. A. Protection against poxvirses. Proc. Res. Soc. Med. 62, 295-297 (1969)

41. Turner, G. S. \& Squires, E. J. Inactivated smallpox vaccine: immunogenicity of inactivated intracellular and extracellular vaccinia virus. J. Gen. Virol. 13, 19-25 (1971).

42. Bradbury, J. Orally available cidofovir derivative active against smallpox. Lancet 359, 1041 (2002).

43. Nomoto, A. \& Arita, I. Eradication of poliomyelitis. Nature Immunol. 3, 205-208 (2002)

44. Alfonso, C. L. et al. The genome of camelpox virus. Virology 295, 1-9 (2002).

45. Ramshaw, I. A. et al. Cytokines and immunity to vira infections. Immunol. Rev. 159, 119-135 (1997).

\section{(1) Online links}

\section{DataBases}

The following terms in this article are linked online to: Entrez: http://www.ncbi.nlm.nih.gov/Entrez/ camelpox | cowpox | HIV-1 | measles | monkeypox | rabies | syphilis | vaccinia | variola | yellow fever

LocusLink: http://www.ncbi.nIm.nih.gov/LocusLink/

IL-4

Medscape Druglnfo: http://www.medscape.com/druginfo cidofovir

\section{FURTHER INFORMATION}

Council of State and Territorial Epidemiologists:

http://www.cste.org/washingtonrpt/010730Washrpt.asp

Dark Winter Exercise: http://www.hopkins-

biodefense.org/darkwinter.html

Smallpox and its Eradication:

http://www.who.int/emc/diseases/smallpox/Smallpoxeradicati on.htm

Statement of Rep. Christopher Shays:

http://www.house.gov/reform/ns/107th_testimony/statement of_rep_shays_july23.htm

The ANSER Institute for Homeland Security:

http://www.homelanddefense.org/darkwinter/index.cfm

World Health Assembly Executive Board:

http://www.who.int/gb/EB_WHA/E/E_Index.htm

Access to this interactive links box is free online. 